\title{
Strategies Men Use to Cope with Stress Caused by Severe Obesity: A Qualitative Study
}

\author{
H.H. van der Spuy, H.M. de Klerk, F.A.M. Wenhold and H.M. Vogel \\ Department of Consumer Science, University of Pretoria, Private Bag x323, \\ Arcadia Pretoria 0007, South Africa \\ E-mail: Esther.vanderspuy@up.ac.za
}

KEYWORDS Obese. Problem-focused Coping. Emotion-focused Coping. Symbolic Interactionist. Life Course

\begin{abstract}
This qualitative study sought to explore and describe the coping strategies obese men use, as well as the lived experience of being obese. A phenomenological approach, symbolic interactionism and life course perspectives were used as theoretical points of departure. Experiences of being obese were described through three individual, in-depth, unstructured interviews. Emotion-focused coping strategies like blaming, denial and reappraisal, as well as avoidance were used while problem-focused coping strategies consisted of physical activity, weight loss diets and wearing appropriate clothes. Cognitive appraisals gave rise to certain emotions and feelings that their self and well-being were at risk and need to be dealt with. Along the life course they developed a specific coping trajectory. Identification of coping strategies and better awareness of the lived experience of obese men may enhance the knowledge of professionals, family members as well as parents who need to support them. It also provided tools to help vulnerable obese people deal with the consequences of stigma associated with it.
\end{abstract}

\section{INTRODUCTION}

The obesity 'epidemic' is one of the most persistent contemporary public health problems prevalent today (Pachucki and Goodman 2015). According to the World Health Organization, obesity is indicated by a BMI greater than 30kg/ $\mathrm{m}^{2}$, whereas when the BMI is greater than $40 \mathrm{~kg} /$ $\mathrm{m}^{2}$, obesity is qualified as morbid (Taylor et al. 2013). Research in obesity demonstrates that there is a widespread, culturally acceptable stereotype and negative attitude towards obese people (Puhl and Heuer 2010). Given that existing approaches to weight loss have limited success and that many overweight people have to cope with stress from the stigma of obesity for years, the lived experience of obesity should be understood in depth (Schafer and Ferraro 2011).

High energy intake frequently and lack of physical activity are seen as the primary causes of obesity. Existing dietary programs and medications can produce no more than an average of ten percent weight loss (Thomas et al. 2008; Puhl and Heuer 2010). There is limited understanding

Address for correspondence:

Dr. Esther van der Spuy

Department of Consumer Science,

University of Pretoria, Private bag x323,

Arcadia Pretoria 0007, South Africa

Telephone: +27(0)124202975

Fax: +27(0)12420 2855

E-mail: Esther.vanderspuy@up.ac.za for why obese individuals cannot take personal responsibility and control for their obese state, which deviates them from an acceptable social norm (Puhl and Heuer 2010; Puhl et al. 2013). Additionally, intervention strategies are separated from its social context as well as environmental and psychological dimensions (Brown 2013). Emotional factors and obese people's relationship with food as stress regulators are not adequately taken into consideration (Glass and McAtee 2006; Puhl and Heuer 2010).

There has been increasing recognition of the seriousness and pervasiveness of the social consequences of being obese.Weight-based publicity has been documented in several areas, which makes obese people vulnerable to stigmas (Schafer and Ferraro 2011; Fettich and Chen 2012). It seems as if prejudice against obese people is still acceptable in society (Thompson and Manor 2010; Taylor et al. 2013).

Understanding weight-based stigmas and the ways people cope with them is important. With so many people living with being overweight and obese, numerous people can be harmed by the stigma associated with stress. Although a lot of research has been done on the type of coping strategies used by obese people to reduce stigma and improve emotional wellbeing (Hilbert et al. 2008; Fettich and Chen 2012; Kwan et al. 2014) more information is needed to develop interventions to reduce bias and to 
change negative stereotypes about obese people (Fettich and Chen 2012). Men and women may also perceive obesity stressors differently and use different coping strategies. Research is needed to examine the relationship between obesity, gender, and coping methods to see whether women and men approach weight-related stigma differently (Puhl and Brownell 2006; Kwan et al. 2014; Castonguay 2015). Rather than using stigma as a motivation to lose weight, supporting individuals with adaptive ways to cope with weight stigma may facilitate weight loss outcomes (Puhl and Heuer 2010).

\section{Background}

Coping is the process of spending mental, conscious energy on dealing with problems in life. It refers to ongoing cognitive, behavioral, and emotional processes in response to the demands of a stressor. Mechanisms used to cope with stress attempt to overcome or diminish the amount of stress experienced (Lazarus and Folkman 1984; Kwan et al. 2014). For the purpose of this paper, Lazarus and Folkman's (1984) classification will be used, namely, emotion-focused and problem-focused coping. Individuals become stressed when demands exceed their coping ability. Emotion-centered coping is an attempt to suppress or otherwise manage the worrying and upsetting emotions a situation causes. Normally emotion-centered coping strategies are internal and private, and are more likely to occur when it has been established and assessed that nothing can be done to prevent harmful threatening conditions. Problem-focused coping, on the other hand, is more likely to be used when appraisal has taken place of conditions that can be changed (Lazarus and Folkman 1984; Lazarus and Lazarus 1994). It changes the way one thinks about the situation from a "threatening to a more benign or positive appraisal” (Lazarus and Lazarus 1994:156). Problem-focused coping strategies are used to deal with the stressor itself while emotion-focused coping strategies are used to minimize negative emotions (Nolen-Hoeksema 2012). The coping strategy that a stigmatized person uses can, in a certain way, be linked to the action that an individual is going to take and how he experiences his self (Lebel 2008). Because a man's gender role is to be more active and energetic, they may be more likely than women to engage in problem-solving and reappraisal, in an attempt to control or change circumstances that cause stress (NolenHoeksema 2012).

Coping can be effective or ineffective with the outcome seemingly dependent on a number of personal and situational factors (Nolen-Hoeksema 2012). Lazarus and Folkman's (1984) transactional model will be used as a framework for evaluating the cognitive processes of appraisal inresponse to stressful events. After an individual has determined the nature of a threat he will appraise resources to deal with the threat and decide on cognitive and/or behavioral actions to deal with the stressor (Lazarus and Folkman 1984; Nolen-Hoeksema 2012).

To shed light on this phenomenon, the theoretical perspectives of symbolic interactionism and a life course approach were used in a larger qualitative study that attempted to explore, understand and describe life course stages and transitions that could be associated with excessive weight gain in men as a high risk element. These perspectives provided conceptual tools and models for constructing a suitable research framework, and for collecting and analyzing data.

Symbolic Interactionism focuses on microphenomena of social interaction. In doing so it creates a participatory, active image of the human being and rejects the image of a human being as a passive organism (Charon 1998; Willis et al. 2007). In this paper, such an assumption would imply that the obese man's action is based on decisions shaped largely by the actual and anticipated responses of others. The obese man's perception of weight stigma and his coping strategies may, therefore, be influenced by the responses of others and how he interprets them. The symbolic interactionism perspective helped the researcher identify and describe others who play a role in the participant's coping trajectories and his experience of the self. Symbolic interactionism can also be applied to the analysis of stigma, a concept of particular interest to health researchers who study obesity (Goffman 1963). People with an obvious physical deformity (like obesity) are made to feel ashamed and experience a "spoiled social identity", which is how they are seen by others. Goffman defined stigma as an "attribute that is deeply discrediting”. It reduces the person who possesses it "from a whole to a tainted, discounted one” (Goffman 1963:2). Goffman (1963) distinguished three sources of stigma: those with 
“abominations of the body", whose appearance is not according to cultural norms for beauty, those with "blemishes of individual character", such as weakness of will, and those with "tribal stigma”. Obese individuals fit into the first two of Goffman's categories. The overweight body is considered physically deviant because of its visibility, but is also strongly associated with lack of willpower and self-control (Lewis et al. 2011).

The life course perspective views peoples' lives across their life course, emphasizing trajectories and transitions while taking into account life stages, social structure and events throughout peoples' lives (Elder in Jabs and Devine 2006; Pachuki and Goodman 2015). Transitions during the life course that are significant for the obese man's coping trajectory and the way he experiences his self, take place in social environments. The developmental impact of the sequence of life transitions or events depends on when they occur in a person's life (Schmidt et al. 2003). The timing of life transitions and events that happen during those transitions, and the presence of others who play a role, have long-term consequences for the obese man's weight trajectory, his experience of the self and subsequent coping strategies. As noted by other scholars (Elder (Jr) 1998; Elder in Heinz and Marshall 2003), this could explain the obese man's experiences of his inner self and how he adapts to external demands while passing through each stage in life.

Both perspectives put emphasis on the important point that the self cannot be separated from the perspectives and opinions of others. The concept of linked lives is particularly true for the obese man who is constantly in interaction with others. His judgment of the self is almost completely in the hands of other people who have great control over the social environment in which he lives (Goffman 1959; Pachuki and Goodman 2015). This means that the obese man judges himself according to the standards of society in terms of physical appearance and work performance.

When studying a phenomenon like obesity, it is useful to examine 'lives in progress' and not to focus solely on a single moment or event. It is also not sufficient to study a series of two to three moments, or established phases or a separate occasion only especially if widely separated in time as happens in longitudinal research. It is necessary to look at obesity in all its complexity, including everything of significance and the interaction with others (Pachuki and Goodman 2015).

\section{Aim and Objectives}

This paper aims to describe the coping strategies a small selected group of obese men used.

The first objective is a deeper understanding of emotional and problem-focused coping strategies used by obese men to handle stress. The second objective is to describe the lived experience of men being obese.

\section{METHODOLOGY}

\section{Design}

A phenomenological and qualitative approach was judged to be most appropriate for the study.The purpose of this paper was to give a rich description of the lived experience of obesity, coping with it, and a deeper understanding of the phenomenon.

The study took place in Tshwane Pretoria, the capital metropolitan city of South Africa. Purposive sampling methods were used to recruit male participants who have experienced being obese. The unit of analysis was an obese, white South African man. White men in South Africa have the highest incidence of obesity compared to all other cultural groups (Kruger et al. 2005; South African Institute of Race Relations, Press release 2013). To be eligible the participant had to be older than 21 years, with a self-reported BMI exceeding $30 \mathrm{~kg} / \mathrm{m}^{2}$, willing to share and the ability to provide a detailed account of his experiences of being obese. In line with the thinking of the theoretical approach, participants were recruited from different life stages. Fourteen participants whose age ranged from 21 to 65 years formed the study sample. Professional and non-professional men at different stages of their lives participated. The degree of obesity of the participants varied between $30 \mathrm{~kg} / \mathrm{m}^{2}$ and $55.6 \mathrm{~kg} / \mathrm{m}^{2}$. Seven of the participants had been obese since childhood while the other seven became obese at a later life stage. With the exception of one, all were married. They had different educational levels and their occupations varied between salesmen, IT consultants, a jeweler, engineers, and an owner of a fast food out- 
let, a law student, a retired rector of a college, a motor mechanic and one participant in the insurance business. Participants are indicated as $R$ numbers (1-14).

\section{Data Collection}

Lengthy (45-60 minutes), individual in-depth unstructured interviews were conducted to gather data (Starks and Trinidad 2013). Three interviews were conducted with each participant. The process consisted of an initial meeting to explain the aim of the study, to build trust and to verify the inclusion criteria; a core interview; and a follow-up interview. This enabled the researchers get an impression of the participants' emotions, thoughts and knowledge of their obese state (see Kvale 1996; Henning et al. 2005) and contributed to data credibility. All the interviews were conducted by the first researcher who had experience in interviewing (Van der Spuy et al. 2003). For referential adequacy, field notes about gestures, emotions expressed and the meeting venue were transcribed immediately after each interview. Interviews were conducted in various settings that were convenient, private and acceptable to the participants, ensuring the protection of their identity. Most of the participants felt more relaxed and less exposed in informal settings such as coffee shops. When participants started to share their emotions and feelings about the lived experience of being obese immediately without any prompting, the information was used during the next interview as a point of departure.

During the second meeting, the interview questions were broad and open-ended. The interview started with: "Tell me something about your experience of being overweight. Where did it all start?" Where necessary, reflective remarks were made to clarify and enhance understanding. As the interviews continued, participants were asked different questions in line with their unfolding stories.

The follow-up interview was conducted to clarify aspects mentioned during the previous interview. Member checks provided participants with an opportunity to elucidate responses, correct misconceptions and provide additional information. This was done to enhance interpretation credibility. Although the researcher primarily used semi-structured questions (based on the core interview), new emerging topics were ac- commodated. The follow-up interviews yielded more data and enriched the overall picture. The participants were more relaxed, adding information after having reflected on the previous interview. The duration of the follow-up interview was between 30 and 45 minutes.

\section{Data Analysis}

Each interview was transcribed and the data was imported into the computer software program, Atlas.ti for the purpose of analysis by the first researcher. It facilitated the organization and management of textual data by attaching codes to certain text passages. The naming of the codes was based on the theory. The use of different approaches to data analysis may lead to better interpretation and understanding (Henning et al. 2005).

Familiarization was done by initially reading through the interview transcripts in full, several times to first gain a sense of the whole picture and to acquire a feeling for the participants' ideas (Svenningsson et al. 2011). The next step was to identify keywords (codes) and sentences relating to the codes. Data was compared and similar incidents were grouped together and given the same conceptual label or code (Smit 2002; Jeon 2004; Henning et al. 2005; Willis et al. 2007). The codes were selected inductively from the data by the first researchers and checked by the others. The analysis thus took place on two levels, namely, the actual words used by the participants and the conceptualization of these words and construction of meaning by 4 independent researchers (Henning et al. 2005). This process was repeated across the 14 participants' stories.

The next step was to select core categories and relate them to the sub-categories. This helped refine and integrate categories and identify definite themes from the research (Creswell 1998; Henning et al. 2005). When codes are meaningfully clustered together and given a descriptive name, the groupings are known as themes. In Atlas.ti, categories are known as families (Archer 2002). Relationships between the categories (families) can be graphically represented using network views to "create a picture of their inner world of meaning” (Travis at al. 2004:408). By creating families and networks in Atlas.ti, complex interactions can be clarified to enhance the researchers' understanding of the situation. This enabled the researchers to identify a sto- 
ryline and identify definite themes in order to give rich thematic descriptions that provided insight into the lived experiences of men being obese.

For the bigger study, three themes emerged from the data, namely, the meanings of food, the sadness of obesity and coping with obesity. In this paper, the third theme is addressed, namely, coping with obesity. The findings cannot be generalized and can only relate to the participants.

\section{FINDINGS}

It became clear that obesity caused distress to most of the participants, especially those participants who have had to bear the consequences of obesity for many years in their lives. Obese participants experienced their physical selves in a very negative way. They had to cope with their overweight bodies. They struggled with immobility and all the physical discomfort that was part of this unfortunate condition. For them it was a constant constrain. In interaction with others they had to cope with the stress that is associated with stereotypes and stigma.

It was clear that the obese participants made use of several coping strategies. To understand their choices and use of coping strategies it is important to be aware of the interplay between the evaluation of the situation, the emotions that follow and the strategies that are chosen. The following sub-themes emerged from the data which will be discussed under two categories, namely, emotion-focused coping and problemfocused coping.

\section{Emotion-focused Coping}

Under emotion-focused coping, the following coping strategies will be discussed: blaming, denial and reappraisal, and avoidance.

\section{Blaming as a Coping Strategy}

The ways in which the obese participants in this study explained their obesity was a way of coping. According to them, their obese state was the result of uncontrollable events and conditions. They might even have experienced an emotion of anger when others perceived their obese state as controllable. They attributed their condition to genetic factors and often remarked that they "came from a big family". It seemed to be a metabolic problem that could not be changed at all. According to them, you would not get a skinny person in a family where the majority of the family members were overweight and there was nothing one could do about genetic hereditary. They used rationalization as a coping strategy. Other participants believed that their weight problems were due to illness. It was an illness that prevented them from losing weight. Providing a medical explanation for obesity reduces the perceived controllability of obesity and increases the belief of others that the obese participant is not responsible for his obese state and this makes him more acceptable (Schafer and Ferraro 2011). Although it did not address the participants' obese problem, the outcome was better for their emotional well-being to put the blame on external factors and not internal factors. Contributory dimensions play an important role in their emotional processing. R12... It [the medication] makes me very tired and nauseous. It is a real problem, because now I do not accelerate my metabolism any more [so I can't lose weight]. R9... but I also have to tell you, because I have thought a lot about the story, I think my problem is genetic... things go wrong in the body and it does not want to burn fat.

Another example of focusing negative attributions for their obese state on external sources for better emotional outcomes, was putting the blame for being obese on their parents and wives. They had to eat the food their wives served and were often spoiled by them. In their childhood they were forced to eat the food served to them. R14... What can I say... I cannot... I do not want to give someone else the blame, but I have grown up in a home where you were told to sit there until you finish your food. R7... I'll put the blame on my wife because she is the one who dishes up the food, but I eat what she gives me.R8... I can wake my wife at two in the morning and say I want chops and eggs and then she will do it. My wife spoils me constantly and I enjoy it.

Most of the participants believed the locus of control for their obese state was outside themselves. They could not do anything about it. It was uncontrollable and permanent. The only thing they could do was to accept the situation. The consequences were that they were not involved in problem-focused coping. The attribu- 
tion process is actually a coping strategy to release the self of blame. They did not need to feel guilty or ashamed. They just needed to accept it.

\section{Denial and Reappraisal as a Coping Strategy}

According to Lazarus and Lazarus (1994), part of emotional coping is to minimize the problem or to deny the existence of the problem. Denial involves situations where the target does not identify with external stereotypes. Some of the participants coped by refusing to acknowledge that they had a weight problem that could have serious consequences for their well-being. They tried to minimize the problem, because denying the existence of the problem help to avoid stress. In reality, it was a weak and temporary coping strategy and did not take the problem away.

The participants said that being overweight was not a problem for them. They were not concerned about weight like women, it did not bother them at all, and they did not concentrate on weight issues, they felt at ease with their bodies. Some of them did not regard themselves to be overweight although they qualified for the obese category. R1... I am extremely overweight, but I do not see myself as overweight I see myself totally differently. I think if I were to see myself, I would be scared (laughs). I do not see myself as a fat person, especially because I am a tall person, and I must add this as I think this is rather important; because I've always been tall (six feet five or 1,9 meters). I have always looked over people. I always look over people; I do not have a problem standing. I am big and tall. My overweight doesn't bother me so much.R8... My weight never was a real issue for me.

The participants appraised situations as negative or positive in terms of their self. When appraising it as a threat to themselves they often then reappraised it in order to see it in a less serious light. Reappraisal is a stronger and more effective coping strategy than denial. It entails the change of personal meaning of things that happened in order to reduce distress (Lazarus and Lazarus 1994). They compared their eating habits with others' drinking and eating habits. This is an example of reappraising a situation to make it less threatening and to compare themselves to others who were worse-off. While oth- ers could not stop drinking (alcoholic beverages) they could not stop eating. According to the participants, a person can stop drinking and say that he will not use alcohol again, but one cannot stop consuming food. This makes it so much more difficult to go on a slimming diet. Reappraisal is a self-protective strategy to buffer oneself from prejudice. R11... Look I have never been a drinker. I never drink a lot of beer or brandy or... I have lots of alcohol in the house, but I never drink it. R1... I think one can draw a line between alcoholism and overeating. They are basically the same type of thing.

Another way to cope with emotions of shame, sadness and guilt was to rely on a strong personality to compensate for being obese. After reappraisal they stated that their stunning personalities compensated for being obese. According to most of the participants, they had a strong self-concept, so being overweight did not bother them or others and even had advantages for them. They thought that their weight gave them a sense of superiority and they did not need to prove themselves. Additionally most of them were over-achievers in terms of work performance: they performed exceptionally well in their careers. Their efforts to achieve in their occupations could also be seen as an attempt to compensate for being obese and to prevent discrimination on the basis of physical appearance. When reappraising their situation they might have thought that, although they were obese, nobody could accuse them of lack of excellence. They constantly gave the assurance that they did not experience discrimination at work at all due to their obese state. They were respected for their work performance. This is another coping mechanism to protect the self and to buffer them against prejudice. $R 14$... A strong self-image helps you cope[with obesity]. R1... Everyone has issues withthemselves because you know yourself better than anyone else knows you. So I think the most important thing is how you feel about yourself, and you must have a good image of yourself. R8... I was big; it was actually to my advantage. I gained respect. R9... I never experienced any feeling that there was discrimination against me because of me being overweight, not with the work situation... my promotion was absolutely fast. R12... I really do not think they discriminated against me... I think it is more about how good you are in your work. R14... No, I do not think they 
discriminated against big guys in the corporate world. I do not want to think too much of myself, but I think my personality makes up for it.

These kinds of coping strategies were mostly used by participants who have been obese since childhood. Living with stigma since childhood may lead to internalization of expectations and stronger pressure to achieve success in other areas so as to be accepted. This may also be an example of reappraising a negative outcome and turn it into something positive.

\section{Avoidance as a Coping Strategy}

In avoidance the individual tries not to think what is troubling him. He draws on all sorts of emotion-centered strategies to smooth the progress of avoidance (Lazarus and Lazarus 1994; Nolen-Hoeksema 2012; Kwan et al. 2014). The participants avoided being compared to the stereotypical icons that compared well to westernized cultural prerequisites. They actually avoided social interaction as a way of escaping devaluation. Some of the participants had to cope with the physical selves and all the negative associations of immobility, discomfort and shame. One way of doing it was to avoid physical challenges and social contact where stigma might be experienced. The participants wanted to forget about their obesity problem and were seen to engage in hobbies that did not require much physical movement. Photography was a very popular past time for a few of them as it did not physically demand too much. A popular holiday option was to visit a game reserve where they were in no way allowed to get out of the car. They managed to become experts in their hobbies and received positive feedback and desired goals in terms of meaningful social interaction. This might be a coping strategy to deal with stigma. R1... And I was sitting in my car. And the big lens is out and we are taking photos, then you send them in and enter a competition. You do not need to climb a mountain to compete. You came last and you were first. (laughs). It is how you adapt in life. People often ask me why I have a yacht. I can sit on the yacht- my family and I. We get onto the yacht on Friday afternoons, we sail around and at night we sleep on our yacht. We never need to walk, because I can't walk on my feet.

\section{Problem-focused Coping}

The participants also made use of problemfocused coping which entailed direct action and support-seeking strategies needed to handle problems they experienced with their physical self and possibly continuous weight gain, as well as emotions of shame, frustration or guilt. Individuals who believe that their stigmatized status is controllable try to remove them from the stigmatized group; in other words obese people try to lose weight. The following problem-focused strategies will be discussed: physical activity, weight loss diets, coping by means of clothes.

\section{Physical Activity}

Some of the participants made use of active coping mechanisms by becoming actively involved in sports and exercise to help with their weight problem. R7... What I do is to swim a lot and one does try to be more active. Since I started exercising I feel more energetic. R6... I do not go to the gym to build muscles. I go to the gym to work off the fat and get fitter. R12... I lost about $5 \mathrm{~kg}$ since we started walking, but I now am going to the gym again.

Unfortunately they did not continue long enough with the physical activity to gain any benefit from it. They often justify why they cannot do exercise. R4... I have a physical problem, so I think that also contributes, it makes it more difficult to get physically active. R9... Then I hurt a muscle in my shoulder; I could not play golf any more. Then my dad died, I took care of my mom and she is now completely incapacitated due to Alzheimer's disease. I had that struggle until the end of last year. R14... Just to get there [gym], takes an hour out of my day.

\section{Weight Loss Diets}

They tried to engage in active coping to regain control by means of weight loss diets. Although the participants pretended that their weight was not a problem for them, they tried several weight loss diets, from a young ageitself. Most often their weight loss efforts lasted only for a short while. Even at a young age (grade 6), some of the participants tried to lose weight. Although some of them were extremely successful in their weight loss program, they eventually 
gained all the weightthat they had lost on again. R9... The diets did not help me a bit. I went on almost every one [diet]. As soon as I stopped the diet, I started climbing back. I went to a doctor in Johannesburg. Then I was really at my fattest. Now he gave me those injections. R1... There are always excuses and until you get to a point where you realize this: there will always be excuses. I'm still going along with the pals. I'm just going to eat less. And the best is not to even tell your pals that you are on a diet because you've been on twenty diets already and they laugh at you, because they know the diets don't work.

The participants did not succeed in reducing obese-related stress. Additionally they experienced shame as an emotion due to their physical appearance and when they were ridiculed by others. It started during adolescence and became worse as time went on. The obese participants knew that they did not comply with westernized cultural ideals for being attractive. They evaluated their bodies as part of their selves. They feared comments that might include negative critique and even rejection by others who were important to them. To cope, they made use of problem-centered coping strategies to handle the emotion of shame. Individuals often use concealment for their unwanted condition as a coping strategy. Unfortunately in the case of obesity their condition does not allow them to do this because their specific problem is quite obvious.

\section{Coping by Means of Clothes}

From the findings it could be assumed that the participants made use of clothes to hide their excess fat from others. In other words, they dressed to cover the parts of their body they did not want to show. Goffman (1963) underlined this need of a person to present themselves to others in a specific manner that is important to them. They indicated that they did not like taking off their shirts especially when they were at the seaside or a swimming pool. They preferred loose fitting clothes and being comfortable. They wore extra-large sizes, especially very big shirts. They also wore black clothes as a coping strategy. They tried to dress correctly and fashionably to cope with their overweight problem. They only wore shirts with buttons and not T-shirts or golf shirts. R7... I got so fat that I could not even hide the fat under the clothing. R8... I buy clothes everywhere that are loose fitting and comfortable. R9... I only wear very big shirts. I will always buy extra-large, so that the rolls do not show. R12... I just wear this type of button shirts. It looks better than when I wear a T-shirt that fits so tightly. I do not wear golf shirts and T-shirts.

\section{DISCUSSION}

The obese man is constantly appraising the significance of what is happening to him and the consequences it has on his well-being. He regularly judges himself and those judgments involve the feelings and emotions he has towards himself. His goal is to protect and enhance his self. When he has dealt with it in a negative way he feels disheartened about his self. These cognitive appraisals give rise to feelings that his well-being is at risk. These emotions are feedback for further appraisal which engenders more emotions (Lazarus 1991; Lazarus and Lazarus 1994; Charon 1998). This is called secondary appraisal. It becomes more challenging as negative appraisals continue. When a person experiences a threat or a challenge, something must be done to undo the stress involved and to manage the situation. Efficacy expectancies are part of secondary appraisal and include the evaluation of different coping capabilities (Lazarus and Folkman 1984; Prati et al. 2010).

According to the Transactional Model (Lazarus and Cohen 1977), a person, faced with a stressor, evaluates the potential threat (primary appraisal). Primary appraisal is a person's judgment about the significance of an event as stressful, positive, controllable, challenging, or irrelevant. Facing a stressor, the second appraisal follows, which is an assessment of the peoples' coping resources and options (Prati et al. 2010). Secondary appraisals address what one can do about the situation.

The obese man's body cannot be separated from the rest of the self. The way he is accepting his body or not will therefore also have consequences for how he experiences the rest of the self (Sandstrom et al. 2006). He constantly estimates how others are evaluating him and this too influences his behavior. His self-concept is based on perceptions of the response of others or internalization of others' judgments and it dif- 
fers in the different life stages and according to the severity of the problem (Castonguay 2015; Pachucki and Goodman 2015).

Against the background of symbolic interactionism, it is not only their own perceptions, standards and experiences of obesity, but also the viewpoints of others and society that influence their experience of the self. Goffman (1959) remarked that meaning of lives has a peculiarly retroactive character. One has to look how age of onset, duration and degree of obesity has an influence on the experience of the self. This implies that the way the obese man experiences obesity depends on the life stage when it commenced and everything that happened during that stage that contributed to emotional consequences. The context in which these processes unfold may also have had an influence. It may coincide with a critical period in an individual's life (Pachucki and Goodman 2015).

According to Nolen-Hoeksema (2012), emotions are evoked by certain stimuli. An individual's goals, desires and expectations interact with personal thoughts and associations coming from actual events to form an effective emotional stimulus. It determines the probability that the event leads to an emotion and also determines the intensity of the emotion (Frijda 2009). These stimuli bring forth emotional responses in reaction to events which are of concern to the individual. Whether an event becomes a stimulus, depends on coping capabilities. When the individual anticipates an unpleasant situation, options for coping are immediately considered. On the basis of what has been learned, the person also foresees the apparent success or failure of the chosen coping effort. Coping abilities determine secondary appraisal. Abilities and inabilities for coping are important in determining whether events become emotional stimuli or not, and in determining which emotions will arise (Lazarus 1991; Nolen-Hoeksema 2012).

Both Lazarus (1991) and Weiner (1986) acknowledged a cognitive approach to emotion and postulated that there is a relationship between how the individual evaluates the situation and the resultingemotions it evokes. In his attribution theory Weiner postulates that "the perceptions of what caused a positive or negative outcome, in part, determine the affective reactions to that outcome" (Weiner 1986:119). Attribution theory thus suggests that people attempt to search for information that determines the causes of a specific condition. Weiner (1986) also acknowledges that initially there is a general positive or negative (primary) emotion involved based on the perceived success or failure of the outcome of the primary appraisal. Success and failure, due to internal causes, are anticipated to respectively result in better or worse experiences of the self. The individual can either experience frustration, joy or sadness. After the outcome is appraised, the individual will seek a causal attribution especially when the outcome is negative or significantly important (Weiner 1986). Contributory dimensions play an important role in the emotion process (Weiner 1986). These emotions are determined by the attainment or non-attainment of a desired goal and not by the cause of the outcome. Following the appraisal of the outcome, a causal response will be sought in terms of whether that outcome was negative, positive, unexpected, important or nonimportant. Causal dimensions play a key role in the emotion process (Weiner 1986). Furthermore, Weiner (1986) stresses that the individual's evaluation of the dimensions of the cause can also influence the emotions experienced afterwards. Internal, stable and controllable causes are typically ascribed to effort, while external, unstable and uncontrollable ascriptions are frequently attributed to luck. Attribution theory attempts to explain how people assign causality, blame or credit, to events, on the basis of their own behavior or the behavior of others (Schiffman and Kanuk 2010).

From a life course perspective one needs to look at the obese man's developmental trajectories of coping and attempt to understand his coping strategies. "Coping is more than simply a strategy; it is a cumulative history of interactive processes that are embedded in developmental organization” (Schmidt et al. 2003:65). Individuals, whose stigma is observable, as in the case of obesity, have to deal with it in social interaction. Interaction, with the others in the coping process must also be considered. Interactions between the developing individual and his developing social world are significantly important. The coping process is part of multiple interactions. The influence of others plays an important role in the way he experiences his self (Kwan et al. 2014).

Stigmatized (obese) individuals can use problem-focused and emotion-focused coping strategies at the same point of time in different cir- 
cumstances, but along the life course they may progress from one coping strategy to the other. They actually have a coping trajectory. The obese man may start early in his coping trajectory with a single reactive coping strategy, and then progress to more proactive coping strategies (Nolen-Hoeksema 2012; Kwan et al. 2014).

\section{CONCLUSION}

Both the emotion-focused and problem-focused coping strategies the participants used could be described and discussed. The coping efforts could have an influence on their emotional well-being and might be helpful. Coping efforts were however complex and might have both positive and negative consequences. For a short while it might improve their emotional well-being but it actually does not take away their obese problem. Even the problem-focused coping strategies only lasted for a while. When they repeatedly experienced failure it caused more stress and negative emotions which needed to be addressed. The experience of the self (physical as well as inner self) was quite often negative with serious implications for their coping capabilities. Over the years, the participants who have been obese since childhood had to adjust their coping strategies on a regular basis because their obese problem has deteriorated. They actually had coping trajectories. Their coping efforts were aimed at regulation of the problem, which gave rise to the outcome of the coping process meaning emotional well-being, functional status, and certain health behaviors. Although the coping strategies did not improve their obeserelated problems, it might diminish stigma-related stress and consequently less coping.

\section{RECOMMENDATIONS}

A better knowledge and awareness of the lived experience of people with obesity may meaningfully enhance the knowledge of professionals and family members who need to support obese individuals. Identification of coping strategies further provides healthcare professionals as well as parents, teachers and family members with tools to help obese people who are vulnerable to consequences of stigma on enhancing effective coping. Obese men should be advised on coping strategies which will contribute to their emotional well-being. More in- formation is needed to develop interventions to reduce bias and to change negative stereotypes about obese people.

\section{REFERENCES}

Archer E 2002. Introduction to Atlas.ti. $2^{\text {nd }}$ Edition. Pretoria: Photostat.

Brown L 2013. Emotions are top obstacle to weight loss. American Psychological Association, 44 (94): 15.

Castonguay AL, Pila E, Wrosch C, Sabiston CM 2014. Body-related self-conscious emotions relate to physical activity motivation and behaviour in men. American Journal of Men's Health, 1-13.

Charon JH 1998. Symbolic Interactionism: An Introduction, an Interpretation, an Integration. $6^{\text {th }}$ Edition. Englewood Cliffs NJ: Prentice Hall.

Cresswell JW 1998. Qualitative Inquiry and Research Design: Choosing among Five Traditions. London: Thousand Oaks Sage.

Devine CM 2005. A life course perspective: Understanding food choices in time, social location, and history. Journal of Nutrition Education and Behaviour, 37(3): 121-128.

Elder Jr GH 1998. Time, human agency, and social change: Perspectives on the life course. Social Psychology Quarterly, 57(1): 4-15.

Fettich KC, Chen EY 2012. Coping with obesity stigma affects depressed mood in African-American and white candidates for bariatric surgery. Obesity, 20(5): 1118-1121.

Frijda NH 2009. Emotions, individual differences and time course: Reflections. Cognition and Emotion, 23(7): 1444-1461.

Glass TA, McAtee MJ 2006. Behavioural science at the crossroads in public health: Extending horizons, envisioning the future. Social Science and Medicine, 62(7): 1650-1671.

Goffman E 1959. Presentation of the Self in Everyday Life. New York: Doubleday.

Goffman E 1963. Stigma: Notes on the Management of Spoiled Identity. New York: Prentice Hall.

Heinz WR, Marshall VW 2003. Social Dynamics of the Life Course: Transitions, Institutions and Interrelations. New York: Aldine de Gruyter.

Henning E, Van Rensburg W, Smit B 2004. Finding Your Way in Qualitative Research.1 ${ }^{\text {st }}$ Edition. Pretoria: Van Schaik.

Hilbert A, Rief W, Braehler E 2008. Stigmatizing attitudes toward obesity in a representative populationbased sample. Obesity, 16(7): 1529-1534.

Jabs J, Devine CM 2006. Time scarcity and food choices: An overview. Appetite, 47: 196-204.

Jeon Y-H 2004. The application of grounded theory and Symbolic Interactionism. Scandinavian Journal of Caring Sciences, 18(3): 249-256.

Kruger HS, Puoanet T, Senekal M, Van der Merwe MT 2005. Obesity in South Africa: Challenges for government and health professions. Public Health $\mathrm{Nu}$ trition, 8(5): 491-500.

Kvale S 1996. Interviews: An Introduction to Qualitative Research Interviewing. London: Sage.

Kwan MY, Gordon KH, Eddy KT, Thomas JJ, Franco DL, Troop-Gordon W 2014. Gender differences in 
coping responses and bulimic symptoms among undergraduate students. Eating Behaviours, 15: 632637.

Lazarus RS 1991. Cognition and motivation in emotion. American Psychologist, 46(4): 352-367.

Lazarus RS, Cohen JB 1977.Environmental stress. In: I Altman, JF Wohlwill (Eds.): Human Behavior and Environment. Volume 2. New York: Plenum, pp. 89127.

Lazarus RS, Folkman S 1984. Stress, Appraisal and Coping. New York: Springer.

Lazarus RS, Lazarus BN 1994. Passion and Reason: Making Sense of Our Emotions. New York: Oxford University Press.

Lebel TP 2008. Perceptions of and responses to stigma. Sociology Compass, 2: 409-432.

Lewis S, Thomas, SL, Blood RW, Castle DJ, Hyde J, Komensaroff PA 2011. How do obese individuals perceive and respond to the different types of obesity stigma that they encounter in their daily lives? A qualitative study. Social Science and Medicine, 73: 1349-1356.

Nolen-Hoeksema S 2012. Emotion regulation and psychology: The role of gender. Annual Review in Clinical Psychology, 8: 161-187.

Pachucki MC, Goodman E 2015. Social relationships and obesity: Benefits of incorporating a lifecourse perspective. Current Obesity Reports, Topical Collection, 2015: Online First Articles, ISSN: 21624968 (Online).

Prati G, Pietantroni L, Cicognanai E 2010. Self-efficacy moderates the relationship between stress appraisal and quality of life among recue workers. Anxiety, Stress, and Coping, 23(4): 463-470.

Puhl RM, Brownell KD 2006. Confronting and coping with weight stigma: An investigation of overweight and obese adults. Obesity, 14: 1802-1815.

Puhl RM, Heuer CA 2010. Obesity stigma: Important considerations for public health. American Journal of Public Health, 100: 1019-1028.

Puhl RM, Gold, JA, Luedicke, JA, De Pierre, JA 2013. The effect of physicians' body weight on patients attitude: Implications for physician selection, trust and adherence to medical advice. International Journal of Obesity, 37: 1415-1421.

Sandstrom KL, Martin DD, Fine GA 2006. Symbols, Selves and Social Reality: A Symbolic Interactionist
Approach to Social Psychology and Sociology. $2^{\text {nd }}$ Edition. Los Angeles: Roxbury.

Schafer MH, Ferraro KF 2011. The stigma of obesity: Does perceived weight discrimination affect identity and physical health? Social Psychology, 74: 76-97.

Schiffman LG, Kanuk LL 2010. Consumer Behaviour. $10^{\text {th }}$ Edition. New York: Prentice-Hall.

Schmidt S, Pietersen C, Bukkinger 2003. Coping with chronic disease from the perspective of children and adolescents - a conceptual framework and its implications for participation. Child: Care, Health and Development, 29: 63-75.

Smit B 2002.Atlas.ti for qualitative data analysis. Perspectives in Education, 20: 65-76.

South Africa Institute of Race Relations 2013. African Women and White Men Weigh in Heaviest. February. Press Release.

Svenningsson I, Hallberg LR-M, Gedda B 2011. Health care professionals meeting with individuals with type 2 diabetes and obesity: Balancing coaching and caution. International Journal of Qualitative Studies for Health and Well-being, 6: 7129-DOI.

Starks H,Trinidad SB 2007. Choose your method: A comparison of phenomenology, discourse analysis, and grounded theory. Qualitative Health Research, 1710: 1372-1380.

Taylor VH, Forhan M, Vigod SN, MCIntyre RS, Morrison KM 2013.The impact of obesity on quality of life. Best Practice and Research Clinical Endocrinology and Metabolism, 27: 139-146.

Thompson J, Manor M 2010. Nutrition: An Applied Approach. $2^{\text {nd }}$ Edition. New York: Pearson.

Travis F, Arenander A, Dubois D 2004. Psychological and physiological characteristics of a proposed object-referral/self-referral continuum of self-awareness. Conscious and Cognition, 13: 401-420.

Van der Spuy E, De Klerk HM, Kruger R 2003. The development of a social-cognitive model for better understanding of the female adolescent suffering from anorexia nervosa. Journal of Family Ecology and Consumer Sciences, 31: 30-39.

Weiner B 1986. An Attributional Theory of Motivation and Emotion. New York: Springer Verlag.

Willis K, Daly J, Kealy M, Small R, Koutroulis G et al. 2007. The essential role of social theory in qualitative public health research. Australian and New Zeeland Journal of Public Health, 31: 438-443. 